\title{
Mucinous cystadenocarcinoma of the pancreas
}

INSERM

\section{Source}

INSERM. (1999). Orphanet: an online rare disease and orphan drug data base. Mucinous cystadenocarcinoma of the pancreas. ORPHA:424053

A rare, epithelial tumor of the pancreas characterized, histologically, by columnar, mucinproducing epithelium associated with ovarian-type subepithelial stroma, which does not communicate with the pancreatic ductal system, most frequently localized to the body or tail of the pancreas. Clinically, small tumors $(<3 \mathrm{~cm})$ are usually asymptomatic, while large tumors typically present obstructive jaundice, a palpable abdominal mass, and may associate portal hypertension, hemobilia and diabetes mellitus. 